\title{
Analysis of Bioactive Minor Compounds in Three Olive Oils from Varieties of Olive Tree Eastern Algerian (Bouricha, Limli and Blanquette)
}

\author{
Benrachou Nora ${ }^{1 *}$, Rahal lynda ${ }^{2}$, Cherifa Henchiri ${ }^{3}$ \\ ${ }^{1}$ Faculty of Science, Department of Agronomy, El Tarf University, 36000, Algeria. \\ 2Department of Biology, Faculty of Sciences, El Tarf University, 36000, Algeria. \\ ${ }^{3}$ Department of Biochemistry, Faculty of Sciences, Badji-Mokhtar University, Annaba-23000, Algeria.
}

\section{Abstract}

The study of bioactive compounds on the health of the unsaponifiable fraction of three olive oils from three cultivars of eastern Algeria carried out by gas chromatography revealed the presence of 11 compounds with the predominance of b-Sitosterol, Sterol characteristic of olive oils and having a nutritional and pharmacological value. The highest content was found in Limli oil (81.59\%). Two triterpene dialcohols were chromatographed with sterols (erythrodiol and uvaol), the content of which can be identified fraud and to detect whether the virgin oil is mixed with the oil of pomace. Analysis of the alcohol fraction by GPC-FID revealed the predominance of a triterpene alcohol, 24-methylene cycloarenol for the three varieties with a higher content for Blanquette (48.03\%) followed by cycloarenol. For the aliphatic alcohols, the analysis shows the predominance of four alcohols with 22, 23, 24 and 28 carbon atoms whose contents are higher for Limli oil. The spectrophotometric determination of antioxidant pigments shows that Limli oil is richer in chlorophylls with an average of $13.53 \mathrm{mg} / \mathrm{kg}$ and a significantly higher carotenoid content for Bouricha and Limli (13.10 - $12.82 \mathrm{mg} / \mathrm{Kg})$. The total polyphenols were lower for Blanquette $(83.36 \mathrm{mg} / \mathrm{kg}$ ) compared with Bouricha and Limli (133.3 $\mathrm{mg} / \mathrm{kg}$ and $121.3 \mathrm{mg} / \mathrm{kg}$ ), making them more stable during oxidation storage and whose beneficial effects of olive oil are mainly attributed to these substances, in particular the antioxidant action that would protect against diseases of oxidative stress.

Keywords: Antioxidant, Bioactive Minor Components, Carotenoid, Olive Oils, Phytosterols

\section{Introduction}

The health benefits of some foods are gaining increasing attention from consumers. In addition to basic nutritional effects, they provide health benefits and also prevent disease.

Olive oil is a "natural functional" food that is both nutritional and curative and contains a high level of
AGMI represented by oleic acid and several bioactive minor components with health benefits.

These compounds are contained in the unsaponifiable fraction; their content varies according to variety, climate, maturity of the olives at harvest the extraction system and the type of oil, common, virgin and extra virgin oil ${ }^{1}$. They represent about $2 \%$ of the weight of the

\footnotetext{
*Author for correspondence

Email:n_benrachou@yahoo.fr
} 
Analysis of Bioactive Minor Compounds in Three Olive Oils from Varieties of Olive Tree Eastern Algerian (Bouricha, Limli and Blanquette)

oil and comprise more than 230 substances belonging to different chemical categories: tocopherols, carotenoids, phenols, volatile compounds, aliphatic and terpene alcohols, aldehydes, chlorophyll and sterols ${ }^{2}$.

Tocopherols, carotenoids and phenols are natural antioxidants, responsible for bitter and spicy sensations but also have valuable therapeutic properties (antioxidant, anti-inflammatory, anti-atherogenic and antimicrobial activity) and can fight against free radicals and reduce risks of chronic diseases such as diabetes, cardiovascular diseases and cancer ${ }^{3}$. Phenolic substances also protect the oil from natural oxidation during storage and give rise to the appearance of rancidity. Sterols represent the major constituents of the unsaponifiable fraction of olive oil (20\%) and are present in free form and esterified with fatty acids ${ }^{4}$, the main ones being $\beta$-sitosterol, $\Delta-5$ avenasterol and campesterol $^{5}$; these substances are opposed to the intestinal absorption of cholesterol and lead to a decrease in hypercholesterolemia ${ }^{6}$.

Triterpenic alcohols are used in pharmaceutical industry for their anti-tumor, anti-inflammatory and germicidal activities ${ }^{7}$.

The chlorophylls a and b, alone or together, are antioxidant in the dark and pro-oxidizing to light, which allows them to play an important role in the stability of the oil during storage ${ }^{8}$ and in the Preservation of its quality $^{8,9}$. A limited number of studies focused on local cultivars, which led us to undertake this work. Among these varieties, Limli, Bouricha and Blanquette, which are widespread in the eastern part of the country and represent about $50 \%$ of the local olive grove, spread over four olive-growing areas: Jijel, Skikda and Guelma ${ }^{10}$. The objective of this study is to determine the richness of bioactive compounds on health such as polyphenols, sterols, tocopherols, carotenoids and chlorophyll, to evaluate their commercial, nutritional and pharmacological quality, which has become a priority with regard to the requirements the international market and the International Olive Oil Council.

\section{Material and methods}

\subsection{Plant Material}

Three oils from three dominant olive varieties in eastern Algeria; mainly in the regions of Jijel, Guelma and Skikda were the subject of this study, namely, Limli, Bouricha and Blanquette.

\subsection{Presentation of Three Varieties}

The olives used in this experiment were harvested from olive trees of three varieties of the ancient olive-growing heritage of eastern Algeria: Bouricha of Guelma, Limli of Jijel and Blanquette of Skikda, campaign 2014-2015.

\subsection{Sampling}

The sampling was carried out on a dozen adult trees during the 2014/2015 olive-growing season and harvested between November and December. A single sample from 10 trees of each variety randomly distributed in the orchard. Each sample consists of $5 \mathrm{~kg}$ of olives exclusively from trees and harvested ${ }^{11}$. The samples were taken from the ITAFV collection in Takariétz (Sidi-Aich). The olives are harvested at the time of maturation corresponding to the phase during which the fruits become rich in oil and acquire all their dietary and organoleptic qualities.

\subsection{Extraction of Oils}

The extraction of the oils was carried out in a oil mill with a two-phase Pieralisie continuous system with a centrifugation making it possible to separate the oil and the pomace wetted by the vegetation waters originating from the olives. The olive oil thus recovered is stored at $4^{\circ}$ C. in the refrigerator, which will then be used for dosing.

\subsection{Determination of the Percentage of Unsaponifiable Matter}

The extraction and dosing method adopted for unsaponifiable matter is that of European Regulation (EEC) No 2568/91. The unsaponifiable content is determined by the following relationship: \% unsaponifiable $=$ Unsaponifiable mass/Mass of the test sample of oil $\times 100$. The method of determination of the sterols is the capillary column GC. In this study, we analyzed so-called bioactive minerals such as sterols, phenolic compounds, pigments (chlorophylls and carotenes), aliphatic and terpene alcohols ${ }^{12}$.

\subsubsection{Determination of Sterols, Erythrodiol and Uvaol}

The method used is that described by the Commission of 
the European Union (Regulation (EEC) No 1348/2013). The unsaponifiable fraction is extracted with ethyl ether. The isolation of the sterols is carried out on thin layer chromatography.

\section{- Preparation of trimethylsilyl ethers:}

The sterols are dissolved with a silylation reagent: pyridine/hexamethyldisilazane/trimethylchlorosilazane: 9:3:1 ( $/$ / v / v). After centrifugation for 2 minutes and standing for 20 minutes, the solution will be used for Analysis by GPC. The silylation should be carried out 15 minutes just before injection.

\section{- Analysis of the silylated extract of the unsaponifiable by GC-FID:}

The filtrate thus obtained is analyzed by GC using a CarloErba type HRGC MEGA series 5160 chromatograph, linked to a Mega series integrator-recorder Carlo-Erba equipped with a flame ionization detector according to the following operating conditions: capillary column (stationary phase $50 \%$ methyl, 50\% phenylpolysiloxane) of $30 \mathrm{~m}$ long and $0.32 \mathrm{~mm}$ of internal diameter with a film thickness of 0 , Temperature of the injector: $300^{\circ} \mathrm{C}$, temperature of the detector (FID): $325^{\circ} \mathrm{C}$, carrier gas: Nitrogen (flow rate: $1 \mathrm{ml} / \mathrm{min}$, quantity injected: 0.2 $\mu \mathrm{l}$. The identification of the peaks is made by reference chromatograms given by the method under the same working conditions (EEC, No 1348/2013) and sets the limits of the relative retention times of the various sterols relative to the cholesterol.

\subsubsection{Determination of Aliphatic and Triterpene Alcohols}

The identification of triterpene and aliphatic alcohols is more difficult than that of sterols, indeed triterpene alcohols are biogenetically the results of various modes of polycyclization and transposition of epoxysqualene ${ }^{13}$. The method used is that given by Regulation (EEC No 796/2002). After isolation of the unsaponifiable material by thin layer chromatography, the band containing the aliphatic and triterpenic alcohols just above the sterols is dissolved in chloroform, filtered and evaporated off the solvent.

\section{- Preparation of trimethylsilyl ethers:}

The alcohols are dissolved with a silinization reagent: pyridine/hexamethyldisilazane/trimethylchlorosilazane: 9:3:1 (v/v/v). After centrifugation for 2 minutes and standing for 20 minutes, the solution will be used for GC analysis. For the quantitative analysis, an internal standard $(0.25 \mathrm{ml}$ of eicosanol) is introduced.

\section{- GC-FID analysis of the alcohol fraction:}

The filtrate thus obtained was analyzed by GC using a Carlo-Erba type HRGC MEGA series 5160 chromatograph, linked to a Carbo-Erba Mega series integrator equipped with a flame ionization detector and Capillary column (stationary phase 50\% methyl, 50\% phenylpolysiloxane) $30 \mathrm{~m}$ long and $0.32 \mathrm{~mm}$ internal diameter with a film thickness of $0.25 \mu \mathrm{m}$. The operating conditions are the same as those of the sterols except that the temperature of the column is not isothermal: the temperature of the furnace is programmed according to a gradient of $3^{\circ} \mathrm{C} . / \mathrm{min}$ : $215^{\circ} \mathrm{C}$. $(5 \mathrm{~min})$ : and increases Up to $290^{\circ} \mathrm{C}$ ( $2 \mathrm{~min}$ ). The identification of the peaks is made by reference chromatograms given by the method under the same working conditions ${ }^{13}$.

\subsubsection{Determination of Total Polyphenols}

The evaluation of the total polyphenols in the oil was expressed in $\mathrm{mg} / \mathrm{kg}$ hydroxytyrosol and was determined according to the colorimetric method with the FolinCiocalteau reagent as described by Montedoro et al ${ }^{14}$. The content of total phenolic compounds was expressed as gallic acid equivalent (GAE) in mg/g of extract ${ }^{15}$.

\subsubsection{Determination of Chlorophyll Content}

The determination of chlorophyll pigment content in olive oil is carried out according to the method described by Wolff and Mosquera Minguez et al ${ }^{16,17}$. It consists of quantification by spectrophotometry at wavelengths of 630, 670 and $710 \mathrm{~nm}$.

The chlorophyll content is given by the following relationship: Chlorophylls $(\mathrm{ppm})=\mathrm{A} 670-(\mathrm{A} 630+$ A710)/2.

\subsubsection{Determination of Carotenoids Content}

This content is determined by a spectrophotometric method according to the method of Mosquera Minguez et $a l^{17}$, the absorption of carotenoids ( $\beta$ carotene), xanthophylls and lutein) shows that they absorb in blue and slightly in the Green with a maximum around 420 , 440 and $460 \mathrm{~nm}$. The absorption at $470 \mathrm{~nm}$ is relative to the fraction of the carotenoids. The carotene content is 
Analysis of Bioactive Minor Compounds in Three Olive Oils from Varieties of Olive Tree Eastern Algerian (Bouricha, Limli and Blanquette)

determined by the following formula: Carotenes (ppm) $=(\mathrm{A} 470 \times 25 \times 10000) /(2000 \times 7.5)^{17}$.

\subsection{Statistical Analysis}

The values of the studied parameters were expressed on average more or less the standard deviation; the number of repetition is 3 . These analyzes were carried out using the software «Minitab statistic Software.

\section{Results}

\subsection{Total Sterols}

Table 1 shows the richness of the three oils to Sterols. Bouricha showed the highest levels (1649.7 mg/kg) followed by the Limli variety $(1524.1 \mathrm{mg} / \mathrm{kg})$ and the Blanquette cultivar with a content of $1370.03 \mathrm{mg} / \mathrm{kg}$.

Table 1: Total sterols of the three oils expressed in $\mathrm{mg} /$ $\mathrm{kg}$

\begin{tabular}{llll}
\hline Cultivar & Bouricha & Limli & Blanquette \\
\hline Total sterols mg/kg & 1649,7 & 1524,1 & 1370,03 \\
\hline Totalsterls $\geq 1000 \mathrm{mg} / \mathrm{kg}(\mathrm{E} C$ regulation). &
\end{tabular}

\subsection{Identification and Quantification of Desmethylsterols, Dialcohols Triterpenic}

The Figure 1 shows the chromatograms of the sterol fraction of the various sterols and Table 2 shows the proportions of the various sterols of the three oils of the three varieties, expressed in \%. Analysis of the sterol fraction reveals the presence of 11 sterol compounds, the most important being $\beta$ sitosterol, $\Delta 5$ avenasterol, campesterol, stigmasterol and clerosterol.

The most abundant of the sterol compounds is $\beta$-Sitosterol, a sterol characteristic of olive oil; The Bouricha and Blanquette varieties have fairly similar levels $(67,69 \%)$ whereas Limli oil is richer in this sterol (81\%). On the other hand, for the $\Delta 5$-Avenasterol, the Bouricha variety is richer than the two other varieties. The levels of campesterol and stigmasterol in the three oils are almost similar. The other sterol compounds are present in very low quantities in all oils. This table also shows two triterpene dialcohols, erythrodiol and uvaol. The amount of erythrodiol is higher in all three than in uvaol $(1.5,0.3)$.

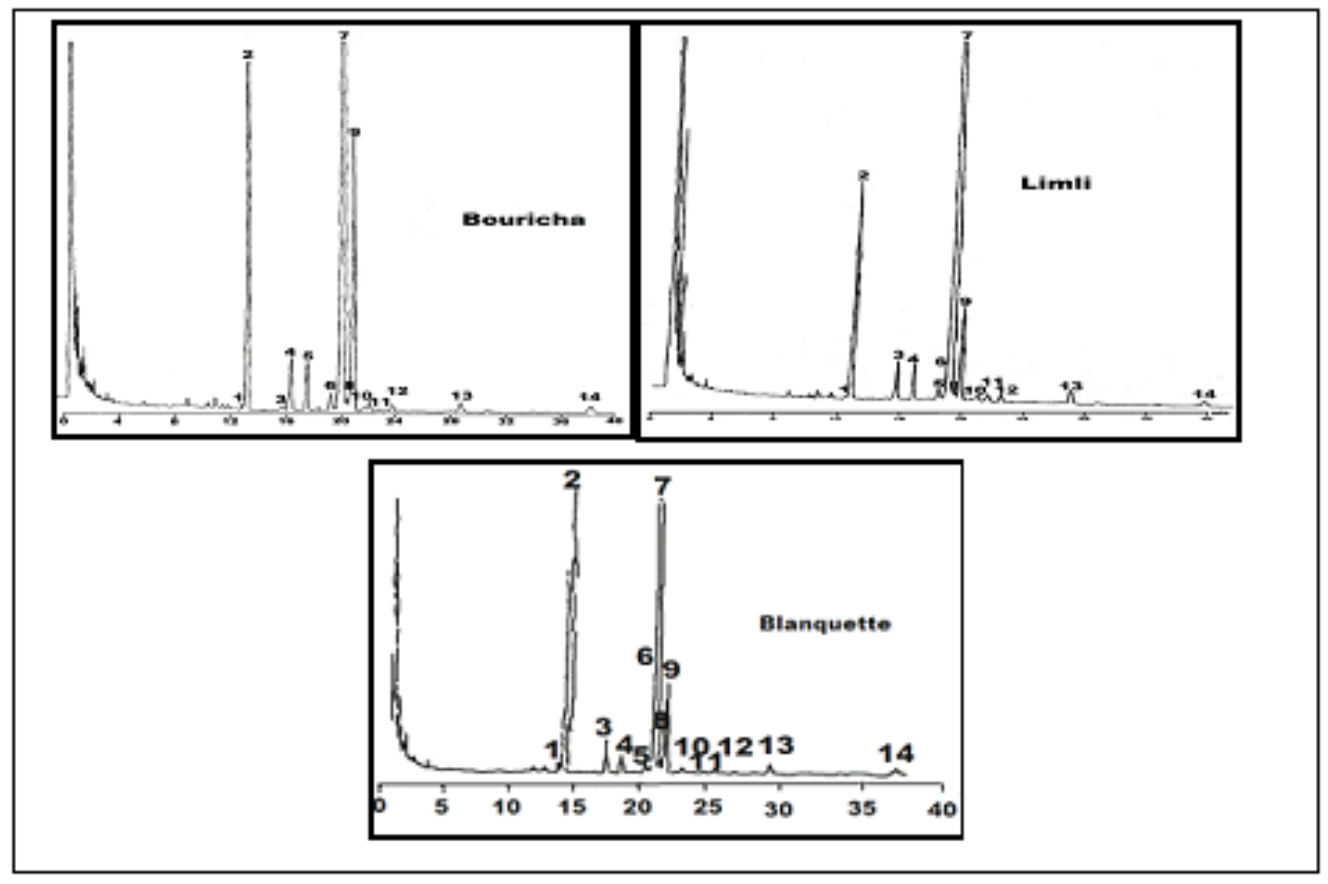

Fig. 1. Chromatogram of the sterol compounds of extra virgin olive oils of the three cultivars. 1: Cholesterol, 2: Internal standard (a-cholestanol), 3: Campesterol, 4: Stigmasterol, 5: $\Delta 7-$ Campesterol, 6: Clerosterol, 7: $\beta$-Sitosterol, 8: Sitostanol, $\Delta 5-24$ Stigmastadienol, 11: $\Delta 7-$ Stigmastenol, 12: $\Delta 7$-Avenasterol, 13: Erythrodiol, 14: Uvaol. 
Table 2: Sterol composition of the three oils expressed in \%

\begin{tabular}{|c|c|c|c|c|}
\hline Cultivar & Bouricha \% & Limli \% & Blanquette \% & Sterol Name \\
\hline \multicolumn{5}{|l|}{ Peak } \\
\hline \multicolumn{5}{|c|}{ Methylsterols } \\
\hline 1 & $0.15 \pm 0.01$ & $0.17 \pm 0.01$ & $0.1 \pm 0.012$ & Cholesterol \\
\hline 2 & $3.23 \pm 0.02$ & $2.97 \pm 0.04$ & $3.15 \pm 0.01$ & Campesterol \\
\hline 3 & $2.15 \pm 0.03$ & $2.62 \pm 0.01$ & $1.55 \pm 0.02$ & Stigmasterol \\
\hline 4 & $0.04 \pm 0.01$ & $0.12 \pm 0.02$ & $0.13 \pm 0.01$ & $\Delta 7$ campesterol \\
\hline 5 & $0.95 \pm 0.02$ & $0.97 \pm 0.01$ & $1.16 \pm 0.02$ & Clerosterol \\
\hline 6 & $67.84 \pm 0.03$ & $81.59 \pm 0.04$ & $69.36 \pm 0.03$ & $\beta$ sitosterol \\
\hline 7 & $0.46 \pm 0.01$ & $0.65 \pm 0.02$ & $0.54 \pm 0.01$ & Sitostanol \\
\hline 8 & $23.20 \pm 0.01$ & $7.79 \pm 0.01$ & $8.99 \pm 0.01$ & $\Delta 5$ avenasterol \\
\hline 9 & $0.63 \pm 0.02$ & $0.25 \pm 0.01$ & $0.54 \pm 0.01$ & $\Delta 5,24$ stigmastadienol \\
\hline 10 & $0.20 \pm 0.01$ & $0.52 \pm 0.02$ & $0.37 \pm 0.01$ & $\Delta 7$ stigmastenol \\
\hline 11 & $0.42 \pm 0.02$ & $0.68 \pm 0.01$ & $0.22 \pm 0.01$ & $\Delta 7$ avenasterol \\
\hline \multicolumn{5}{|c|}{ Triterpenic Dialcohols } \\
\hline 12 & $1.68 \pm 0.01$ & $1.54 \pm 0.01$ & $1.53 \pm 0.01$ & Erythrodiol \\
\hline 13 & $0.23 \pm 0.01$ & $0.36 \pm 0.01$ & $0.33 \pm 0.01$ & Uvaol \\
\hline
\end{tabular}

Limits established by EEC regulations: cholesterol $\leq 0.5 \%$, campesterol $\leq 4.0 \%$, stigmasterol $<$ campesterol, $\Delta 7$-stigmasterol $\leq 0.5 \%$.

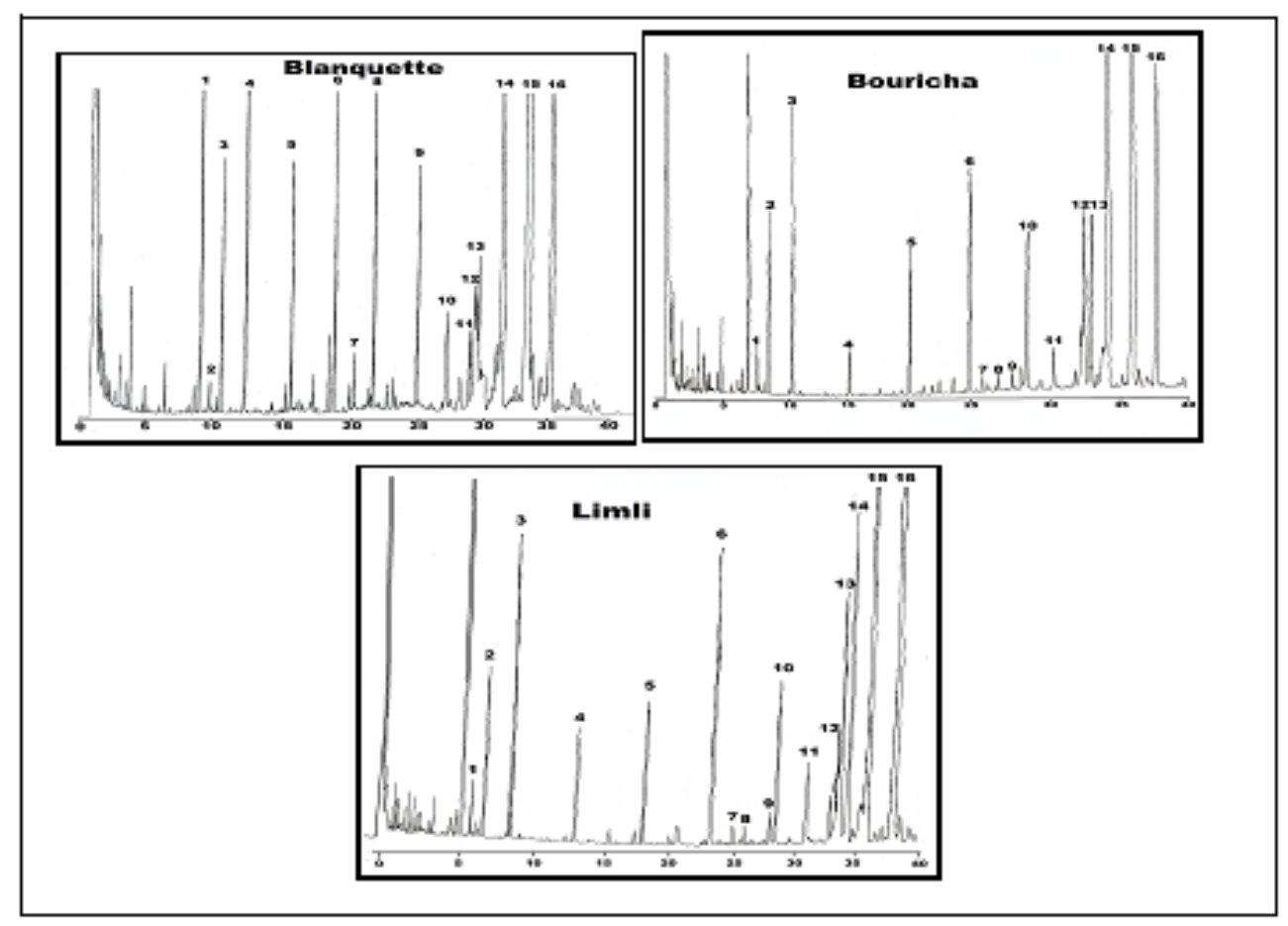

Fig.2. GC/FIDchromatographicprofileofthealcohols oftheoliveoils ofthethreevarieties. 1 : Phytol, 2 : Geranil-geraniol, 3-Eicosanol C20 (standard) , 4 : Docosanol C22, 5 :Tricosanol C23, 6 : Tetracosanol C24, 7: Pentacosanol C25, 8 : Hexacosanol C26, 9 : Heptacosanol C27, 10 : Octacosanol C28, 11 : Butyrospermol , $12: \beta$-amirin, 13 : $\alpha$-amirin, $14:$ Cycloartenol, 15 :24-methylene cycloartenol, 16 : Citrostadienol. 
Analysis of Bioactive Minor Compounds in Three Olive Oils from Varieties of Olive Tree Eastern Algerian (Bouricha, Limli and Blanquette)

\subsection{Non-Cyclic Aliphatic, Di-Terpene and Triterpene Composition}

Figure 2 shows several compounds of different structures chromatographed together: Aliphatic alcohols, the content of which in the three oils shows the predominance of the C 24 alcohol with a higher content for the olive oil of the Limli variety $(3,98 \%)$ followed by the $\mathrm{C} 23$ alcohol which has a higher content for the Blanquette variety.

However, octacosanol (C28) and docosanol (C22) are found to be higher in Limli olive oil. The other alcohols, C25, C26 and C27 are present in the trace amounts in the three oils. Tetracyclic triterpene alcohols: butyrospermol in quantities lower than those of cycloartenol and methylene cycloartenol. The pentacyclic triterpene alcohols: $\alpha$ amyrin and $\beta$ amyrin in average amounts relative to the other compounds. Citrostadenol in higher amounts in all oils.

Table 3 shows the aliphatic alcohol composition (\%) of the three oils. Three alcohols dominate namely C24, C23 and C22. This composition exceeds the limit set by EEC $\mathrm{x}$ regulation, i.e., $6.05 \%$ for Bouricha; $10.43 \%$ for Limli and 9.94\% for Blanquette.

Table 4 shows the composition of diterpene dialcohols and triterpene alcohols of the three oils. Two non-cyclic di-terpene alcohols are identified; Geranyl geraniol presents higher percentages than phytol. Similarly, the three oils contain several triterpene alcohols; Methylancycloclo- malol alone represents the highest level, mostly in Blanquette oil, followed by cycloarenol, citrostadienol, $\beta$ amyrin, $\alpha$-amyrin and butyrospermol.

Table 3: Aliphatic alcohol composition (\%)

\begin{tabular}{lllll}
\cline { 1 - 1 } \multicolumn{1}{l}{ Cultivars } & Bouricha $\%$ & Limli $\%$ & Blanquette $\%$ & Alcohol \\
\cline { 1 - 4 } 4 & & & & \\
5 & $0.59 \pm 0.02$ & $1.40 \pm 0.01$ & $1.34 \pm 0.01$ & Docosanole C22 \\
6 & $1.80 \pm 0.02$ & $1.89 \pm 0.01$ & $3.33 \pm 0.01$ & Tricosanole C23 \\
7 & $2.79 \pm 0.01$ & $3.98 \pm 0.02$ & $2.82 \pm 0.03$ & Tétracosanole C24 \\
8 & $0.19 \pm 0.01$ & $0.07 \pm 0.01$ & $0.08 \pm 0.01$ & Pentacosanole C25 \\
09 & $0.26 \pm 0.01$ & $0.24 \pm 0.01$ & $0.16 \pm 0.01$ & Hexacosanole C26 \\
10 & $0.20 \pm 0.01$ & $0.42 \pm 0.02$ & $0.42 \pm 0.02$ & Heptacosanole C27 \\
\cline { 1 - 3 } & $0.22 \pm 0.01$ & $2.43 \pm 0.01$ & $1.79 \pm 0.01$ & Octacosanole C28 \\
\hline
\end{tabular}

Table 4: Composition in Diterpene dialcohols and triterpene alcohols of the three oils

\begin{tabular}{|c|c|c|c|c|}
\hline Cultivar Peak & Bouricha\% & Limli \% & $\begin{array}{l}\text { Blanquette } \\
\%\end{array}$ & Name of Alcohols \\
\hline \multicolumn{5}{|c|}{ No cyclic diterpenic Alcohols } \\
\hline 1 & $0.46 \pm 0.01$ & $0.49 \pm 0.01$ & $0.16 \pm 0.01$ & Phytol \\
\hline 2 & $1.65 \pm 0.03$ & $1.66 \pm 0.01$ & $2.44 \pm 0.01$ & Geranyl geraniol \\
\hline \multicolumn{5}{|c|}{ Triterpenic Alcools } \\
\hline 11 & $0.65 \pm 0.01$ & $1.39 \pm 0.01$ & $0.66 \pm 0.01$ & Butyrospermol \\
\hline 12 & $5.76 \pm 0.02$ & $6.34 \pm 0.03$ & $2.19 \pm 0.01$ & $\beta$ amyrin \\
\hline 13 & $3.78 \pm 0.01$ & $7.01 \pm 0.03$ & $3.81 \pm 0.01$ & a amyrin \\
\hline 14 & $29.05 \pm 0.01$ & $20.33 \pm 0.02$ & $29.62 \pm 0.02$ & Cycloartenol \\
\hline 15 & $42.34 \pm 0.01$ & $43.96 \pm 0.04$ & $48.03 \pm 0.03$ & 24 methylencycloartenol \\
\hline 16 & $8.24 \pm 0.01$ & $8.39 \pm 0.01$ & $3.35 \pm 0.01$ & Citrostadienol \\
\hline
\end{tabular}




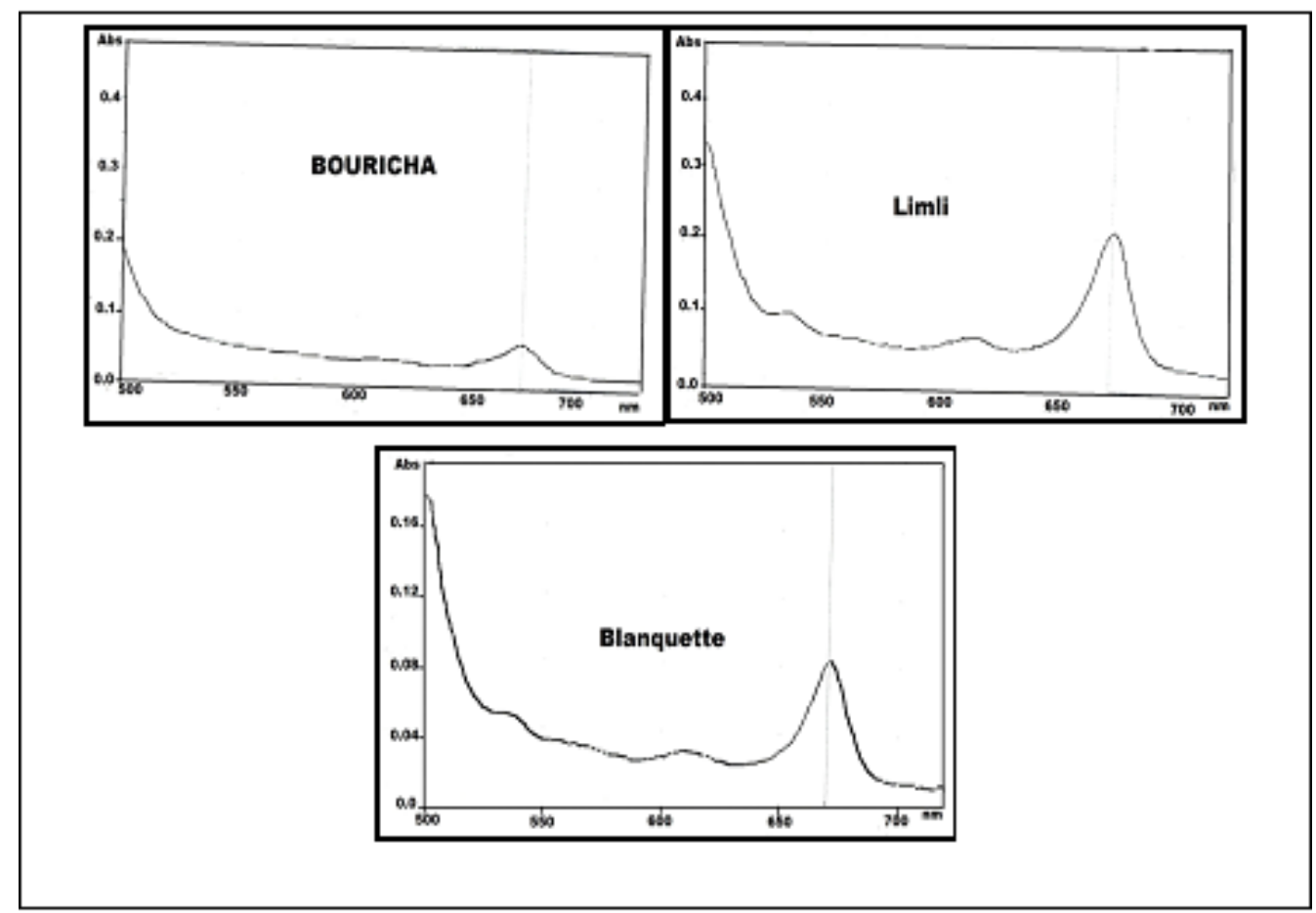

Fig. 3. Absorption spectrum of chlorophyll from olive oils of the three varieties.

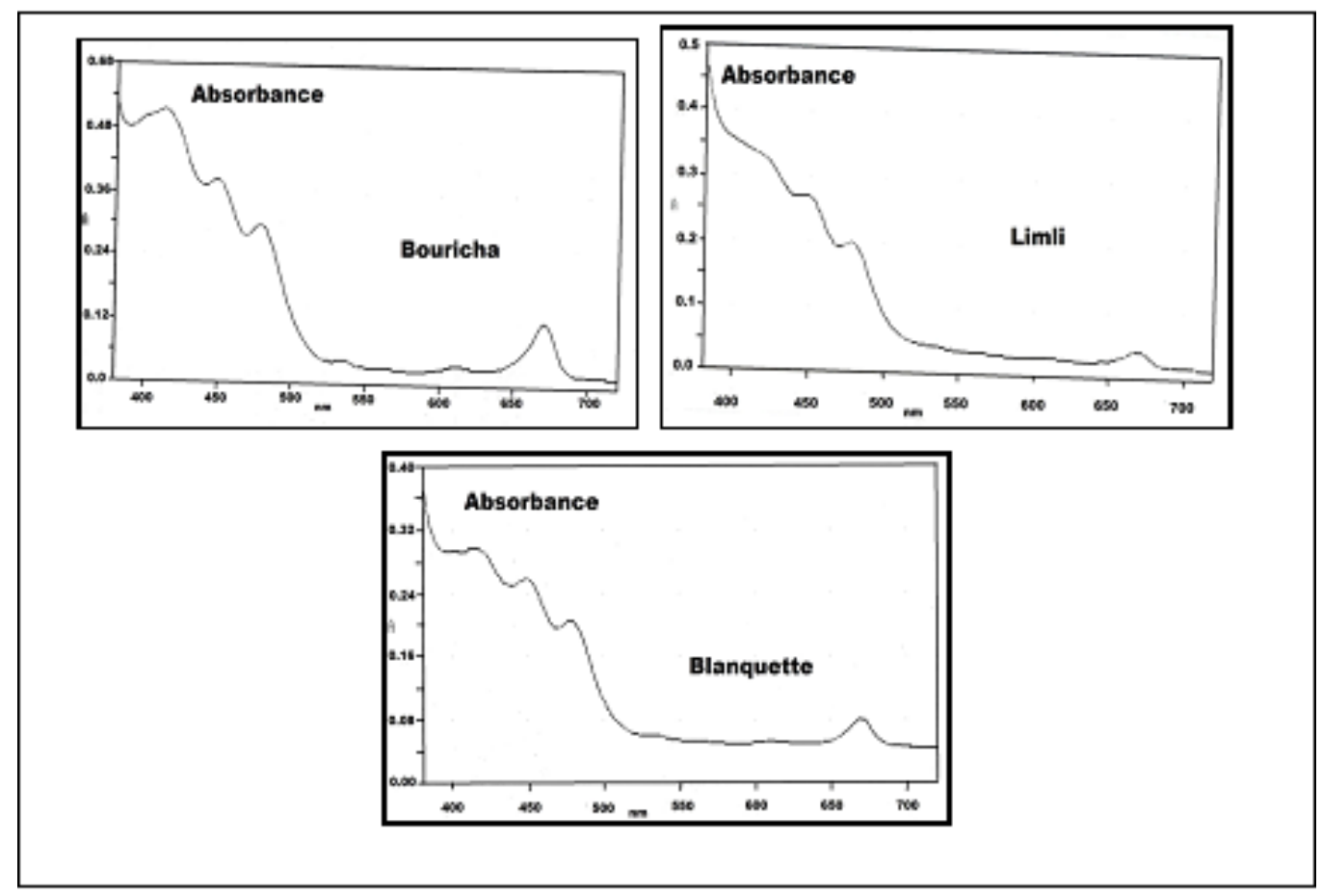

Fig. 4. Absorption spectrum of carotenoids of virgin olive oils of the three varieties. 
Analysis of Bioactive Minor Compounds in Three Olive Oils from Varieties of Olive Tree Eastern Algerian (Bouricha, Limli and Blanquette)

\subsection{Colour Pigments}

\subsubsection{Chlorophylls}

Figure 3 shows the spectra of the crude chlorophylls of the three oils. Peaks between $500 \mathrm{~nm}$ and $700 \mathrm{~nm}$ corresponding to the crude chlorophyll are observed, the maximum absorption between 500 and $520 \mathrm{~nm}$.

Table 5 gives the chlorophyll contents expressed in ppm of the varieties of olive oils studied. The chlorophyll content of the Blanquette oil (13.53 ppm) is the highest.

Table 5: Chlorophylls contents expressed in ppm

\begin{tabular}{llll}
\hline Cultivar & Bouricha & Limli & Blanquette \\
\hline Chlorophylls (ppm) & $10,03 \pm 0,03$ & $11,06 \pm 0,01$ & $13,53 \pm 0,01$ \\
\hline
\end{tabular}

\subsubsection{Carotenoids}

Figure 4 shows the spectra of the crude carotenoids of the three oils. Different absorption peaks are observed as a function of the wavelength (peaks between 350-500 $\mathrm{nm}$ and between 600-700 $\mathrm{nm}$ ).

Table 6 shows the crude carotenoid composition of the olive oils analyzed, showing that the Bouricha and Limli oil are richer in carotenoids.

Table 6: Carotenoids contents, expressed in $\mathrm{mg}$ of $\beta$-carotene $/ \mathrm{kg}$ of oil

\begin{tabular}{llll}
\hline Cultivar & Bouricha & Limli & Blanquette \\
\hline $\begin{array}{l}\text { Carotenoïds } \\
\text { (mg/100g) }\end{array}$ & $13,10 \pm 0,02$ & $12,82 \pm 0,04$ & $10 \pm 0,01$ \\
\hline
\end{tabular}

\subsection{Total Polyphenols}

Table 7 shows that the three oils contain an appreciable amount of phenolic compounds with a predominance in the Bouricha variety.

Table 7: Composition in total polyphenols expressed in $\mathrm{mg} / \mathrm{kg}$ of caffeic acid

\begin{tabular}{llll}
\hline Cultivar & Bouricha & Limli & Blanquette \\
\hline Total Polyphenols & $133,3 \pm 0,01$ & $121,3 \pm 0,01$ & $83,36 \pm 0,03$ \\
$\mathrm{mg} / \mathrm{kg}$ & & & \\
\hline
\end{tabular}

\section{Discussion}

Extra Virgin Olive Oil (EVOO) has biological and therapeutic value and is considered a functional food. Its antioxidant, anti-inflammatory, anti-atherogenic and hypolipidemic and other biological functions 1,2,3 are attributed to its chemical composition rich in AGMI and minor compounds such as sterols, fatty alcohols, diterpenes, triterpenes, polyphenols and carotenoids1 Boscou. In this study we will try to discuss the results of each constituent and its relationship with health.

Table 1 shows that all the varieties studied have sterol contents above $1000 \mathrm{mg} / \mathrm{kg}$ of oil, the minimum value required by the European Union Regulation on the marketing of olive oil. These oils are rich in sterols especially Bouricha oil. These levels, according to some authors, depend on several factors, including fruit maturation and variety ${ }^{18}$, as well as extraction processes and storage conditions ${ }^{19}$.

The evaluation of the sterol content is of great interest and is used to characterize: the origin of each olive oil, to classify them according to variety and origin, to verify their authenticity and to detect fraud Possibly ${ }^{20}$; They are also important compounds for the stability of olive oils because they preserve it from the high temperature by acting as inhibitors of polymerization reactions ${ }^{21}$.

Similarly, their importance on health is related to their structural analogy with cholesterol, which gives them a cholesterol-lowering role when they are brought in sufficient quantities in the food ration because they then compete with dietary cholesterol and decrease Absorption $^{22}$.They also exhibit anti-inflammatory, antibacterial, anti-fungal, anti-tumor and anti-ulcerative properties $^{23}$.

Figure 1 and Table 2 show the chromatographic profile of the sterol fraction and triterpene dialcohols. The three oils are characterized by the predominance of four sterols: $\beta$-sitosterol, campesterol, $+\Delta$-5-avenasterol and stigmasterol. The other sterols in these oils are: cholesterol, $\Delta$-7-campesterol, clerosterol, $\Delta-5,25-$ stigmastadienol, $\Delta-7$-stigmasterol and $\Delta-7$-avenasterol. These results are consistent with those of various authors who reported that $\beta$-sitosterol, $\Delta 5$-Avenasterol, and campesterol are the most important sterols of olive oils of Spanish varieties ${ }^{24}$ and of Portugal ${ }^{25}$, the other sterols are in low quantity ${ }^{4}$.

The highest mean value of $\beta$-Sitosterol is observed for olive oil of the Limli variety, $81.59 \%$, similar to the Tunisian Chetoui variety reported by Bentemime $S$. et al., $2008^{26}$. The three varieties studied have a composition in campesterol ranging from $3.25 \%$ to $3.97 \%$ on average, in accordance with EEC Regulation No. 2568/91, which 
sets a limit of $4 \%$. These results agree with those of the authors on Spanish olive oils ${ }^{27}$ and on Tunisian olive $\mathrm{oils}^{28}$. Stigmasterol is a parameter that reflects the quality of the oil; In fact its content shows a high correlation with acidity $^{29}$ and varies with the organoleptic characteristics of olive oil $^{30}$. Oils with higher stigmasterol than campesterol are classified at a low level (Lampante olive oil).

As for the relation of these sterols to health, studies have shown that the effects of sterols of olive oil are attributed to $\beta$ sitosterol, the main sterol of olive oil, It decreases the level of LDL cholesterol, opposes the intestinal absorption of cholesterol, has antitumor activity and plays a role in the prevention of certain cancers (prostate, colon) ${ }^{31}$. On the other hand, $\Delta 5$ Avenasterol is associated with antioxidant activity ${ }^{32}$. Two triterpene alcohols are chromatographed with sterols, erythrodiol and uvaol; Their determination may be useful for the detection of olive oil in virgin olive oil. According to EEC regulations, the level of erythrodiol + uvaol should not exceed $4.5 \%$ for virgin olive oil. (EEC Regulation 2013). These results are consistent with those of various authors who have worked on Spanish olive oils ${ }^{34}$ and on Tunisian olive oils ${ }^{28}$. Compared to the percentages of the sterols, those of erythrodiol and uvaol provide information on the oils obtained mechanically and extracted by solvent; their evaluation is essential for a good identification of the types of oils ${ }^{35}$. Similarly, the erythrodiol content makes it possible to distinguish the stage of maturity of the oils. Food Chemistry ${ }^{36}$.

The aliphatic alcohol composition of the three varieties exceeds the limit laid down by the EEC regulation, namely $6,05 \%$ for Bouricha; $10.43 \%$ for Limli and $9.94 \%$ for Blanquette (Table 3). This could be due to the methods of extraction of the oils, since according to the authors ${ }^{14}$. the methods of extraction of oils strongly influences this content. According to Salvador et al, chlorophyll concentrations can range from 80 $\mathrm{mg} / \mathrm{k}$ for olive oils in early stages of maturity to $2 \mathrm{mg} /$ $\mathrm{kg}$ if the fruit is fairly walled ${ }^{18}$, the levels of pigments, chlorophylls and carotenoids vary between 1 and $54.4 \mathrm{mg}$ / $\mathrm{kg}$ of chlorophylls and 2.6 to $22.5 \mathrm{mg} / \mathrm{kg}$ of carotenes; Whereas Šarolić et al. ${ }^{38}$ showed that this variation is 3.86 to $4.75 \mathrm{mg} / \mathrm{kg}$ of chlorophylls and 1.89 to $2.06 \mathrm{mg} /$ $\mathrm{kg}$ of carotenes. The pigment contents are in the range of Mosquera and superior to those of Sarolic; They are also superior to those of Algerian varieties, Chemlal of the other regions, Sigoise, Tableout and Frantoio found by Zegane et al. ${ }^{39}$ ( 1 to 2.8 for chlorophylls and 0.7 to $1.7 \mathrm{mg} / \mathrm{kg}$ for carotenoids).

Chlorophylls and carotenoids are dyes of olive oil, they play an important role in the oxidative activity of the product due to their antioxidant nature in the dark and pro-oxidant in the light. A low chlorophyll content reduces the risk of oxidation ${ }^{40}$. Many studies argue that chlorophylls and their derivatives have antioxidant properties $^{41}$, the therapeutic properties of chlorophyll and its derivatives are numerous among which can be cited the prevention against certain cancers, normalize the blood pressure, Stimulate the Immune system and detoxification of the liver ${ }^{42}$.

In vitro and animal studies have shown that carotenoids can protect against several types of cancer ${ }^{43}$ and are also unique constituents of a healthy diet and play an important role as antioxidant vitamins. Vitamin A, the main carotenoid to promote growth, embryonic development and visual function ${ }^{44}$. Carotenoids also induce Phase I and Phase II metabolic enzymes that play a role in the detoxification of carcinogens ${ }^{45}$.

The oils studied have average polyphenol contents of $133 \mathrm{mg} / \mathrm{kg}$ Bouricha, $121 \mathrm{mg} / \mathrm{kg}$ Limli and $83 \mathrm{mg} / \mathrm{k}$ blanquette, are comparable to those found by Benaziza and Semad ${ }^{46}$ for other Algerian oils with grades between 116.50 and $241.33 \mathrm{mg} / \mathrm{kg}$. They are much lower than those of Moroccan varieties which oscillate between 182 and $514 \mathrm{mg} / \mathrm{kg}$. Phenolic compounds pass into the oil during extraction. They are considered natural antioxidants which protect the oil against oxidation and give it better storage stability and a bitter flavor ${ }^{40}$. These variations can be due to the difference in the maturity of the olives before trituration (early harvest of the olives) of the cultivated variety and the geographical area ${ }^{47}$.

The beneficial effects of olive oil are mainly attributed to polyphenols, in particular the antioxidant action. These compounds can exert an antioxidant effect in vivo, in particular in the postprandial phase according to Bonanome et al. ${ }^{48}$ They are also considered as dietary nutrients of the Mediterranean diet ${ }^{49}$.

According to a study carried out by a European group, two oils were tested: a virgin olive oil very rich in polyphenols $(366 \mathrm{mg} / \mathrm{kg})$, a mixed oil obtained from a mixture of virgin olive oil, Refined olive oil, moderately 
Analysis of Bioactive Minor Compounds in Three Olive Oils from Varieties of Olive Tree Eastern Algerian (Bouricha, Limli and Blanquette)

rich in polyphenols $(164 \mathrm{mg} / \mathrm{kg})$, showed that olive oil rich in polyphenols exhibits antioxidant action and increases HDL-cholesterol ${ }^{50}$.

\section{Conclusion}

The purpose of this study was to evaluate three varieties of olive oils of the olive-growing heritage of eastern Algeria by determining the minor compounds of the unsaponifiable fraction of these oils which has a high organoleptic, pharmacological and commercial They can meet the expectations of consumers who are increasingly demanding for their health. There is a difference in the richness of the oils in minor compounds depending on the geographical area and the variety, Bouricha oil of Guelma is the richest.

It would be necessary to extend this work to these varieties for several olive crop years to confirm these results and to other local varieties and thus raise awareness among farmers to improve the techniques for the cultivation, storage, processing and preservation of olive oils To ensure their quality. Further research is needed on the health benefits of olive oils, including the role of minor compounds.

\section{References}

1. Servili M, Selvaggini R, Esposto S, Taticchi A, Montedoro G. and Morozzi M. Health and sensory properties of virgin olive oil hydrophylic phenols: Agronomic and technological aspects of production that affect their occurrence in the oil. Journal of Chromatography A. 2004; 1054(1-2):113-27. https://doi.org/10.1016/S00219673(04)01423-2

2. Servili M, Montedoro G. Contribution of phenolic compound in virgin olive oil quality. European Journal of Lipid Science and Technology. 2002; 104:602-13. https:// doi.org/10.1002/1438-9312(200210)104:9/10<602::AIDEJLT602>3.0.CO;2-X

3. Cicerale S, Lucas L, Keast R. Biological activities of phenolic compounds present in Virgin Olive Oil. Int J Mol Sci. 2010; 11(2):458-79. PMid:20386648 PMCid:PMC2852848. https://doi.org/10.3390/ijms11020458

4. Phillips KM, Ruggio DM, Toivo JI, Swank MA. Simpkins $\mathrm{AH}$. Free and esterified sterol composition of edible oils and fats. J Food Compos Anal. 2002; 15:123-42. https:// doi.org/10.1006/jfca.2001.1044
5. Boskou D, Blekas G, Tsimidou M. Olive oil composition. Boskou DD, editor. Olive Oil, Chemistry and Technology. 2nd ed. Champaign Illinois: American Oil Chemists Society; 2006. p. 41-72. PMid:17110101.

6. Hendriks HF, Weststrate JA, van Vliet T, Meijer GW. Spreads enriched with three different levels of vegetable oil sterols and the degree of cholesterol lowering in normocholesterolaemic and mildly hypercholesterolaemic subjects. Eur J Clin Nutr. 1999; 53:319-27. PMid:10334658. https://doi.org/10.1038/sj.ejcn.1600728

7. Herrera MD, Rodriguez-Rodriguez R, Ruiz-Gutierrez V. Fonctional properties of pentacyclic triterpenes contained in « Orujo » olive oil. Current Nutr Food Sci. 2006; 2:45-9. https://doi.org/10.2174/157340106775471976

8. Tekaya IB, Hassouna M. Étude de la stabilité oxydative de l'huile dolive vierge extra tunisienne au cours de son stockage). OCL. 2005; 12(5-6):447-54. https://doi. org/10.1051/ocl.2005.0447

9. Giuffrida D, Salvo F, Salvo A, La Pera L, Dugo G. Pigments composition in monovarietal virgin olive oils from various Sicilian olive varieties. Food Chemistry. 2007; 101:833-7. https://doi.org/10.1016/j.foodchem.2005.12.030

10. Rebour H. Situation actuelle de loléiculture en Algérie. Alger. 2005; 46:1-6.

11. COI/OH/ Doc. No 1. Novembre 2011.Guide pour la détermination des caractéristiques des olives à huile.

12. COI/T.20/Doc. No 30/Rev. 1. Method of analysis determination of the composition and content of sterols and Triterpene dialcohols by Capillary column gas chromatography; 2013 Nov.

13. Lopez-Lopez A, Monta-o A, Ruiz-Mendez MV, GarridoFernandez A. Sterols, fatty alcohols, and triterpenic alcohols in commercial table olives. Journal of the American Oil Chemists Society. 2008; 85:253-62. https:// doi.org/10.1007/s11746-007-1186-6

14. Montedoro G, Servili M, Baldioli M, Miniati E. Simple and hydrolyzable phenolic compounds in virgin olive oil. 2. Initial characterization of the hydrolyzable fraction. J Agric Food Chem. 1992; 40(9):1577-80. https://doi. org/10.1021/jf00021a020

15. Roncero AV, Del Valle CJ. Determination de la teneur en polyphenols totaux dans l'huile d'olive. Grasas y Aceites. 1973; 24(6):350-7.

16. Wolff JP. Manuel d'analyse des corps gras. Paris: Azoulay. 1968. p. 245.

17. Minguez MIM, Rejano L, Guandul B, Sanchez AH, Garido J. Color pigment, correlation in virgin olive oil. J 
Am Oil Chem. 1991; 68:332-6. https://doi.org/10.1007/ BF02657688

18. Giuffre AM, Louadj L, Poiana M, Macario A. Sterol composition of oils extracted from olives cultivars of the province of Reggio Calabria (south of Italy). Riv Ital Delle Sostanze Grasse. 2012; 89(3):177-83.

19. Gracia S. Composicion quimica de distintas calidades de aceites de oliva virgen de la variedad "Empeltre" en el bajo Aragón. Grasas Aceites. 2001; 52(1):52-8.

20. Ranalli A, Pollastri L, Contento S, Di Loreto G, Iannucci E, Lucera L. Sterol and alcohol components of seeds, pulp, whole olive fruit oils. Their use to characterise olive fruit variety by multivariates. Journal of the Science of Food and Agriculture. 2002; 82:854-9. https://doi.org/10.1002/ jsfa. 1116

21. Sims RJ, Fioriti JA, Kanuk MJ. Sterol additives aspolymerization inhibitors for frying oils. J Am Oil Chem Soc. 1972; 49:298-301. https://doi.org/10.1007/ BF02637578

22. Konuskan DB. Mungan B. Effects of variety, maturation and growing region on chemical properties, fatty acid and sterol compositions of virgin olive oils. J Am Oil Chem Soc. 2016; 93:1499-508. https://doi.org/10.1007/s11746016-2904-8

23. Quillez J, Garcila-Lorda P, Salas-Salvadol J. Potential uses and benefits of phytosterols in diet: Present situation and future directions. Clin Nutr. 2003; 22:343-51. https://doi. org/10.1016/S0261-5614(03)00060-8

24. Pardo JE, Cuesta MA, Alvarruiz A. Evaluation of potential and real quality of virgin olive oil from the designation of origin'Aceite Campo de Montiel (Ciudal Real, Spain). Food Chem. 2007; 100:977-84. https://doi.org/10.1016/j. foodchem.2005.10.059

25. Alves MR, Cunha SC, Amaral JS, Pereira JA, Oliveira MB. Classification of PDO olive oils on the basis of their sterol composition by multivariate analysis. Analytica Chimica Acta. 2005; 549:166-78. https://doi.org/10.1016/j. aca.2005.06.033

26. Temime SB, Manai H, Methenni K, Baccouri B, Abaza L, Daoud D, Casas JS, Bueno EO, Zarrouk M. Sterolic composition of Chéetoui virgin olive oil: Influence of geographical origin. Food Chem. 2008 ; 110:368-74. PMid:26049228. https://doi.org/10.1016/j. foodchem.2008.02.012

27. Stiti N, Msallem M, Triki S, Cherif A. Etude de la fraction insaponifiable de l'huile d'olive de differentes varietes Tunisiennes. La Rivista Italiana delle Sostanze Grasse. 2002; 79(10):357-63.
28. Gutierrez F, Varona I, Albi MA. Relation of acidity and sensory quality with sterol content of olive oil from stored fruit. J Agric Food Chem. 2000; 48:1106-10. PMid:10775357. https://doi.org/10.1021/jf9907337

29. Gracia MS, Benavente-Garcia O, Castillo J, Lorente J, Ortuno A, Del Rio JA. Antioxidant activity of phenolics extracted from Olea europaea $L$ leaves. Food Chemistry. $2000 ; \quad 68: 457-62 . \quad$ https://doi.org/10.1016/S03088146(99)00221-6

30. Ostlund RE Jr. Phytosterols in human nutrition. Annu Rev Nutr. 2002; 22:533-49. PMid:12055357. https://doi. org/10.1146/annurev.nutr.22.020702.075220

31 Ambavade SD, Misar AV, Ambavade PD. Pharmacological, nutritional, and analytical aspects of $\beta$-sitosterol: A review. Oriental Pharmacy and Experimental Medicine. 2014; 14(3):193-211. https://doi.org/10.1007/s13596-014-01519

32. Homapour M, Ghavami M, Piravi-Vanak Z, Hosseini SE. Chemical properties of virgin olive oil from Iranian cultivars grown in the Fadak and Gilvan regions. Grasas Aceites. 2014; 65(4):e043. https://doi.org/10.3989/ gya.0351141

33. Pardo JE, Cuesta MA, Alvarruiz A. Evaluation of potential and real quality of virgin olive oil from the designation of origin' Aceite Campo de Montiel (Ciudal Real,Spain). Food Chem. 2007; 100:977-84. https://doi.org/10.1016/j. foodchem.2005.10.059

34. Mariani C, Bellan G, Morchio G, Pellgrino A. Free and esterified minors compoments of olive and hazelnut: Their potential utilisation in checking oil blend. Rivista italiana delle sostanze grasse. 1999; 76(7/8):297-305.

35. Fuentes de Mendoza M, De Miguel Gordillo C, Expoxito JM, Sanchez Casas J, Cano MM, Vertedor DM, Baltasar MNF. Chemical composition of virgin olive oils according to the ripening in olives. Food Chemistry. 2013; 141:2575-81. PMid:23870997. https://doi.org/10.1016/j. foodchem.2013.05.074

36. Sarolic M, Gugic M, Friganovic E, Giovanni Tuberoso CI, Jerkovic I. Phytochemicals and other characteristics of Croatian monovarietal extra virgin olive oils from Oblica, Lastovka and Levantinka varieties. Molecules. 2015; 20:4395-409. PMid:25759956. https://doi.org/10.3390/ molecules 20034395

37. Zegane O, Keciri S, Louaileche H. Physicochemical characteristics and pigment content of algerian olive oils: effect of olive cultivar and geographical origin. International Journal of Chemical and Biomolecular Science. 2015; 1(3):153-7. 
Analysis of Bioactive Minor Compounds in Three Olive Oils from Varieties of Olive Tree Eastern Algerian (Bouricha, Limli and Blanquette)

38. Tanouti K, Serghini-Caid H, Chaieb E, Benali A, Harkous M, Elamrani A. Quality improvement of olive oils produced in the eastern Morocco. Les technologies de Laboratoire. 2011; 6(22):1-12.

39. Hoshina C, Tomita K, Shioi Y. Antioxidant activity of chlorophylls: its structure activity relationship. Photosynthesis: Mechanisms Effects. 1998; 4:3281-4.

40. Ferruzzi MG, Blakeslee J. Digestion, absorption, and cancer preventative activity of dietary chlorophyll derivatives. Nutrition Research. 2007; 27:1-12. https://doi. org/10.1016/j.nutres.2006.12.003

41. Hsu C-Y, Chao P-Y, Hu S-P, Yang CM. The antioxidant and free radical scavenging activities of chlorophylls and pheophytins. Food and Nutrition Sciences. 2013; 4:1-8. https://doi.org/10.4236/fns.2013.48A001

42. Mayne ST. Beta-carotene, carotenoids, and disease prevention in humans. FASEB. 1996; 10:690-701.

43. Stahl W, Sies H. Bioactivity and protective effects of natural carotenoids. Biochimica et Biophysica Acta. 2005; 1740:101-7. PMid:15949675. https://doi.org/10.1016/j. bbadis.2004.12.006

44. Benaziza A, Semad D. Oleiculture: Caracterisation de six variétés dolives introduites dans le sud-est Algerien. European Scientific Journal Novembre. 2016; 12:537-53.

45. Garcia A, Brenes M, Garcia P, Romero C, Garrido A. Phenolic content of commercial olive oils. European Food Research and Technology. 2003; 216(6):520-5. https://doi. org/10.1007/s00217-003-0706-3
46. Bonanome A, Pagnan A, Caruso D, Toia A, Xamin A, Fedeli E, Berra B, Zamburlini A, Ursini F, Galli G. Evidence of postprandial absorption of olive oil phenols in humans. Nutrition Metabolism and Cardiovascular Diseases. 2000; 10:111-20. PMid:11006919.

47. Edwin N. Frankel. Nutritional and biological properties of extra virgin olive oil. J Agri Food Chem. 2011; 59(3):78592. PMid:21210703. https://doi.org/10.1021/jf103813t

48. Covas MI, Nyyssonen K, Poulsen HE, Kaikkonen J, Zunft HJ, Kiesewetter H, Gaddi A, de la Torre R, Mursu J, Baumler H, Nascetti S, Salonen JT, Fito M, Virtanen J, Marrugat J, EUROLIVE Study Group. The effect of polyphenols in olive oil on heart disease risk factors: A randomized trial. Ann Intern Med. 2006; 145(5):333-41. https://doi.org/10.7326/0003-4819-145-5-20060905000006

49. Edwin N. Frankel. Lipid oxidation. 2nd ed. University of California, USA: The Oily Press 2005. p. 486.

50. Hernaez A, Fernandez-Castillejo S, Farras M, Catalan U, Subirana I, Montes R, Sola R, Mu-oz-Aguayo D, Gelabert-Gorgues A, Diaz-Gil O, Nyyssonen K, Zunft HJ, De La Torre R, Martin-Pelaez S, Pedret A, Remaley AT, Covas MI, Fito M. Olive oil polyphenols enhance highdensity lipoprotein function in humans: a randomized controlled trial. Arterioscler Thromb Vasc Biol. 2014 Sep; 34(9):2115-9. PMid:25060792. https://doi.org/10.1161/ ATVBAHA.114.303374 